\title{
THE DEMAND FOR CULTURAL SERVICES IN KOREA USING THE QUAIDS MODEL
}

\author{
Suyoung Yoon \\ Chung-Ang University \\ Shik Heo* \\ Chung-Ang University
}

\begin{abstract}
In order to investigate the demand for cultural services in Korea, we employ a QUAIDS model based on neoclassical microeconomic theory and estimate demand on cultural services, i.e., SR (Sports and Recreation), CEP (Cinema, Exhibition and Performing arts), and BC (Broadcasting and Content). We try to ascertain Korean households' responsiveness to price and income changes as well as substitution and complementary relationships among cultural services. According to our results, the demands for cultural services in Korean households were more sensitive to price than income. Furthermore, our results showed that SR and CEP are a mutually complementary, while both SR and CEP are substitutes for BC. More specifically, this study is extended to the demand for cultural services by households' characteristics. We found that main customers in CEP are female, while and those in SR are male. Additionally, both SR and CEP customers have higher incomes and price elasticity in older households, but opposite is true in households with higher education levels. Finally, BC has higher income elasticity in households over the age of 50 than other age groups. Our results may expect to provide some insight into government organizations to promote the arts and culture sector.
\end{abstract}

Keywords: Cultural Services; QUAIDS Model, Income and Price Elasticities, Complementary and Substitutes, Korea.

\section{INTRODUCTION}

Nowadays, many scholars assert that cultural industries play an increasingly important role in development and evolution of an economy. In Korea, cultural industries are recently receiving the attention as a new economic growth engine. Due to current enthusiasm for Korean television, K-pop such as Gangnam Style, so called 'Hanryu', i.e., Korean wave throughout the world, Korean cultural industries sales have increased. The exports amount in cultural industries increased by $\$ 312$ million from 2012 to 2013, which is a growth rate of $6.8 \%$, and the annual average export growth rate was $17.2 \%$ from 2009 to 2013 .

- Corresponding author: School of Economics, Chung-Ang University, 84 Heukseok-Ro, Dongjak-Gu, Seoul, Korea. Tel.: +82 2820 5560. E-mail addresses: shikheo@cau.ac.kr (S. Heo) 
Figure 1. presents the average budget share of each expenditure for Korean households from 2005 to 2013. As shown in Figure 1, the expenditure shares of education, transportation, restaurants, and hotels tend to reduce or be stagnant, while the expenditure shares of health, communication, entertainment and culture tend to rise. The budget share of households for entertainment and culture has been consistently increasing from $4.7 \%$ to $5.9 \%$ and the annual average budget growth rate was 3.6\% from 2005 to 2013 .

Figure 1: The average budget share of each expenditure for Korean household

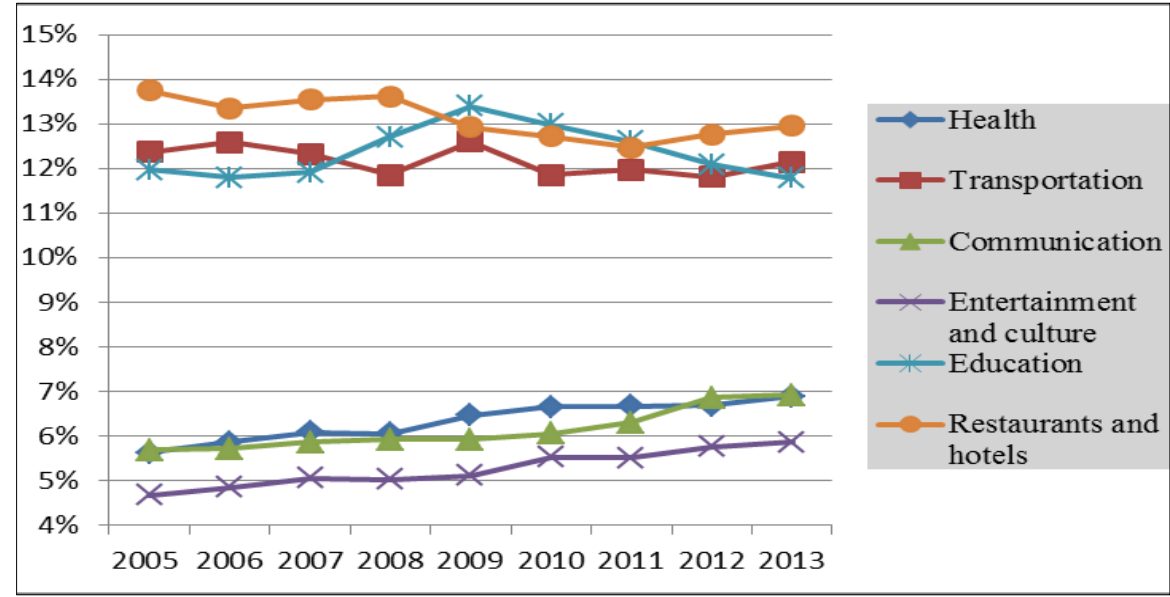

Source: own calculations are based on average monthly income and expenditure statistics provided by the Korean Statistical Information Service.

Notes: we omit the expenditure share of necessities (e.g. food, clothing, and shelter, etc.)

Although the global market size of cultural industries in Korea is the world's $8^{\text {th }}$ largest with $\$ 48$ billion, the absolute size is far behind other developed countries (Korea Creative Content Agency 2014). Domestically, the small market size of Korean cultural industries may be the biggest obstacle to continuing market expansion, because most of the sales in cultural industries rely heavily on the domestic market. Nevertheless, along with a recent rise in exports and household expenditures in the arts and culture sector, the Korean government has crafted supporting policies on cultural industries. According to Ringstad and Løyland (2011), policy enforcement without the exact information about cultural supply and demand can lack efficiency and validity and thus do not appraise them accurately. Many overseas researchers have been focused on the demand-side studies. In Korea, even demand-side studies have not been conducted. Thus the purpose of this paper is to investigate the demand for cultural services domestically, based on Korean household survey data.

Previous demand-side research for cultural industries have focused on the determinants of individual demand in specific industries; e.g. cinema, literature, media, performing arts, etc. Most of the related studies were focused on the socio-demographic characteristics and cultural capital accumulation as the determinant factors of product demand in a specific cultural industry (Ateca-Amestoy 2008; Borgonovi 2004; Montgomery and Robinson 2006; Muñiz et al. 2014; Pawlowski and Breuer 2012; Seaman 2006). These studies did not consider relationships between consumption expenditure items, since they used a 
single equation model. Hence, these studies are somewhat inadequate to create a complete demand system in the cultural industries. In order to overcome these shortcomings, we use a QUAIDS (Quadratic Almost Ideal Demand System) model which is a simultaneous demand system used in the previous studies (Lee and Lee 2012; Lee and Choi 2011; Prieto-Rodriguez 2005). However, these studies do not account for the socio-demographic factors which can have a significant impact on the household demand for cultural services. If the chosen model does not include socio-demographic characteristics in the simultaneous demand system, omitted variable bias problems can occur (Cameron and Trivedi 2005; Ringstad and Løyland 2009, 2011). Accordingly, socio-demographic features of households are included in the QUAIDS model.

We used three categories of cultural services used in our analysis: SR (Sports and Recreation), CEP (Cinema, Exhibition and Performing arts), and BC (Broadcasting and Contents). With the rapid growth of new media in Korea, the proportion of broadcasting and online/mobile content has increased considerably. We expect that the demand for BC has had a significant effect on the expenditure patterns of other cultural services (e.g. SR, CEP) and non-cultural commodities. In practice, cultural services can be diversely specified by various fields. For example, in Montgomery and Robinson's study (2006), they were interested in the determinants of participation in dance, orchestra, opera, theater, professional sports, amateur sports, movies, clubs, rock concerts, and comedy shows. However, since proper disaggregated data is not provided and the sample size is small in some cases, we are focused on three broad categories of cultural services, that is, sports related activities (SR), arts related activities (CEP), and multimedia related activities (BC).

This paper seeks to investigate the overall demand for cultural services by estimating the average customer income and price elasticity of three categories. This analysis can help us determine whether the household demand for cultural services differs based on price and average annual income. Utilizing the QUAIDS model to check cross price elasticity, we found substitution and complementary relationships among cultural services. More specifically, this analysis examines the household demand for cultural services using the following characteristics; gender, age, and education level. We expect our results to provide a better understanding of household cultural services consumption behaviors in Korea. It is our goal to provide the necessary information to foster effective promotion by government organizations in the arts and culture sector. Section 2 examines the literature and research of demand-side studies on arts and culture sector. Section 3 introduces the QUAIDS model and the estimation method. In Section 4, the data used in our analysis is explained and Section 5 presents the empirical results of overall demand patterns of cultural services in Korea. In the last section, we summarize the empirical results and provide some implications for government organizations to promote the arts and culture sector.

\section{LITERATURE REVIEW}

There are two different approaches to investigating the demand for goods or services, i.e., a single equation model and a complete demand system model. The former specifies a demand function directly without reference to the utility function, while the latter is based on the microeconomic consumption theory and allows us to estimate a complete demand 
system (Chang \& Serletis, 2014). The single equation model for demand analysis is the traditional approach, which has been conducted more times than a complete demand system model.

Montgomery and Robinson (2006) investigated participant characteristics in sports, arts, and popular arts in the United States using an Arts Participation Survey. According to their results, frequent sports attendees were also the most frequent attendees of other arts events, and cinema was substituted for most of other arts events. Using a panel of 59 Flemish theaters over the period 1980-2000, Werck and Heymdels (2007) showed that the income elasticity varies from 1.7 to 2.35 and the estimated price elasticity has a lower value $(0.15)$ than others. Furthermore, the artistic output characteristics, such as cast size, Dutch speaking playwrights, and revivals guarantee had a positive effect on attendance. In Zieba's study (2009), she estimated the demand for German public theatre using 178 theaters over the period 1965 to 2004, employing a fixed effect model. As a result, the price for performing arts was inelastic and the full-income elasticity had a higher value (5.65) than the disposable income elasticity (1.16). In this study theatre tours, modern and advanced technical standard of stage design, and the average wage of the cast had a positive influence on theater attendance. Pawlowski and Breuer (2012) estimated Tobit type 1 and type 2 models with data drawn from German Continuous Household Budget Survey (CHBS) in 2006. They found that the estimated elasticity using the type 1 model is more than unity, while the elasticity using the type 2 model is less than unity. Muñiz et al. (2014) analyzed sports and cultural events demand using a count data model and a Spanish Time Use Survey (TUS) from the 2002-2003. Their results showed that seasonality and large cities have a positive influence on the demand for sports and cultural events.

At this point there has not been enough research to apply a complete demand system model on the demand for the arts and culture sector. Prieto-Rodriguez et al. (2005) explored the Spanish demand for cultural commodities employing the Almost Ideal Demand System (AIDS) model. As a result, the income elasticity for CTM (cinema, theatre, museum, etc.) was 1.75, BPN (book, magazine and newspaper) 1.37, and RFA (Records, films and audio-visual media) 1.24. They also found that CTM and BPN are complements and RFA is mutual substitute for both CTM and BPN. Using the QUAIDS model to examine Norwegian books demand, Ringstad and Løyland (2006) showed that the income elasticity of the demand for books (1.3) is more than unity and thus books are luxury goods, and the price elasticity of books demand was elastic and books are substitutes for other cultural services. Later, Ringstad and Løyland (2009, 2011) investigated the demand for cultural commodities using Norwegian household survey data from 1986 to 2002. Their results showed that the demand for performing arts is income elastic, while cinema is income inelastic. The demand for both the performing arts and cinema is price inelastic, and they are substitutes to each other as well as to other cultural/media goods. A notable finding is that performing arts has a complementary relationship with sports and AV media. This data suggests that decreases in the prices of sports and AV media stimulate the demand for performing arts.

There are few empirical studies on Korean cultural services using the complete demand system model. Using the AIDS model, Lee and Choi (2011) explored the aggregated demand of cultural services using the annual Korean Household Income and Expenditure 
Survey data from 1982 to 2007 . They found household expenditure on cultural services is more sensitive to changes in price and income compared to other types of expenditures. Moreover, performing arts services, cultural facility services, and other cultural services are complementary goods, while these services are substitutes for sports \& recreation services. Also using the AIDS model, Lee and Lee (2012) examined the household demand for telecommunications in Korea due to the recent sharp increase in the share of telecommunications expenditure. They found that telecommunications services are complements for transportation, books \& printed matter, and cultural \& recreation services, but substitutes for cultural \& recreation durable goods.

There are some differences between previous studies and ours. First, instead of the AIDS model, we use the QUAIDS model, which adds an additional quadratic term to account for non-linear Engel curves caused by differences in expenditure shares among households at different income levels. Second, omitted variable bias problems can occur if the model does not include socio-demographic characteristics in the simultaneous demand system (Cameron and Trivedi 2005; Ringstad and Løyland 2009, 2011). Accordingly, the socio-demographic features of Korean households are included in the QUAIDS model.

\section{THE QUAIDS MODEL}

Calculating consumer demand for commodities begins with the estimation of demand equations derived from neoclassical consumer theory. Numerous flexible demand systems have been proposed so far, for instance, the Translog model of Christensen et al. (1975), the Almost Ideal Demand System (AIDS) of Deaton and Muellbauer (1980), and the Quadratic Almost Ideal Demand System (QUAIDS) of Banks, Blundell and Lewbel (1997). The QUAIDS model used in our empirical analysis is based upon the AIDS model and allows to a more general Engel curve shape. This model is designed to estimate a complete demand system consistent with both microeconomic theory and available expenditure and price data (Oliver, 2014). Oliver (2014) mentions that, through the addition of the quadratic income term, the QUAIDS model allows goods to be luxuries at some income levels but necessities at others. The QUAIDS model generates a rank three system and is based upon the following indirect utility function:

$\ln \mathrm{V}(\mathrm{P}, \mathrm{m})=\left[\left\{\frac{\ln m-\ln a(\mathrm{P})}{b(\mathrm{P})}\right\}^{-1}+\lambda(\mathrm{P})\right]^{-1}$

where the term in the brace is the indirect utility function of a Price-Independent Generalized Logarithmic (PIGLOG) demand system, $\mathrm{m}$ indicates total expenditures of households, and $\mathrm{P}$ represents a vector of prices. $\mathrm{a}(\mathrm{P})$ is a differentiable and homogeneous function of degree one in prices. $\lambda(\mathrm{P})$ and $\mathrm{b}(\mathrm{P})$ are homogeneous functions of degree zero in prices. These functions are defined as:

$$
\begin{aligned}
& \ln a(\mathrm{P})=\alpha_{0}+\sum_{i=1}^{k} \alpha_{i} \ln p_{i}+\frac{1}{2} \sum_{i=1}^{k} \sum_{j=1}^{k} \gamma_{i j} \ln p_{i} \ln p_{j} \\
& b(\mathrm{P})=\prod_{i=1}^{k} p_{i}^{\beta_{i}}
\end{aligned}
$$


$\lambda(\mathrm{P})=\sum_{i=1}^{k} \lambda_{i} \ln p_{i}$, where $\sum_{i=1}^{k} \lambda_{i}=0$

Applying the Roy's identity to the indirect utility function (1), the budget share equation for commodity $i$ is

$w_{i}=\frac{\partial \ln a(\mathrm{P})}{\partial \ln p_{i}}+\frac{\partial \ln b(\mathrm{P})}{\partial \ln p_{i}}(\ln m)+\frac{\partial \lambda}{\partial \ln p_{i}} \frac{1}{b(\mathrm{P})}(\ln m)^{2}$

where $w_{i}$ is defined as $w_{i}=p_{i} q_{i} / m$ representing the budget share for commodity $i$. In order to be consistent with the microeconomic theory, the parameters should impose the restrictive conditions that (i) aggregation: $\sum_{i=1}^{k} \alpha_{i}=1, \sum_{i=1}^{k} \beta_{i}=0, \sum_{j=1}^{k} \gamma_{i j}=0$, (ii) homogeneity: $\sum_{j=1}^{k} \gamma_{i j}=0$, and (iii) symmetry: $\gamma_{i j}=\gamma_{j i}$.

Replacing (2), (3) and (4) in (5), we get the QUAIDS expenditure share equation:

$w_{i}=\alpha_{i}+\sum_{j=1}^{k} \gamma_{i j} \ln p_{j}+\beta_{i} \ln \left\{\frac{m}{a(\mathbf{p})}\right\}+\frac{\lambda_{i}}{b(\mathbf{p})}\left[\ln \left\{\frac{m}{a(\mathbf{p})}\right\}\right]^{2}$

In order to analyze the demand system including socio-demographic factors, we employ the Ray's (1983) scaling technique introduced by Poi (2012):

$e_{h}(\mathrm{P}, \mathrm{z}, \mathrm{u})=\overline{m_{0}}(\mathrm{z}) \times \Phi(\mathrm{P}, \mathrm{z}, u) \times e^{R}(\mathrm{P}, u)$

where $\mathrm{e}_{h}(\mathrm{P}, \mathrm{z}, \mathrm{u})$ is the household's expenditures as a function of the price vector $\mathrm{P}$, the socio-demographic vector $\mathrm{z}$, and utility u. $\overline{m_{0}}(z) \times \Phi(\mathrm{P}, z, u)$ scales the expenditure function to account for demographic characteristic, with $\overline{m_{0}}(z)$ representing the effect of socio-demographic characteristics on total expenditure and $\Phi(\mathrm{P}, z, u)$ representing the effect of those characteristics on relative expenditure and must be homogeneous of degree zero in price and utility. Let $e^{R}(\mathrm{P}, u)$ denote the expenditure function of a reference household composed of just a single adult. Following Ray (1983), we can parameterize $\overline{m_{0}}(z)$ as:

$\overline{m_{0}}(z)=1+\rho^{\prime} z$

where $\rho$ is a vector of estimating parameters. Following Poi (2002), $\ln \Phi(\mathrm{P}, z, u)$ defines:

$\ln \Phi(\mathrm{P}, z, u)=\frac{\prod_{j=1}^{k} p_{j}^{\beta_{j}}\left(\prod_{j=1}^{k} p_{j}^{\eta_{j}^{\prime} z}-1\right)}{\frac{1}{u}-\sum_{j=1}^{k} \lambda_{j} \ln p_{j}}$

Then, we obtain the following expenditure share equation model with sociodemographic characteristics:

$w_{i}=\alpha_{i}+\sum_{j=1}^{k} \gamma_{i j} \ln p_{j}+\left(\beta_{i}+\boldsymbol{\eta}_{i}^{\prime} \mathbf{z}\right) \ln \left\{\frac{m}{\overline{m_{0}}(\mathbf{z}) a(\mathbf{p})}\right\}+\frac{\lambda_{i}}{b(\mathbf{p}) c(\mathbf{p}, \mathbf{z})}\left[\ln \left\{\frac{m}{\overline{m_{0}}(\mathbf{z}) a(\mathbf{p})}\right\}\right]^{2}$ 
where

$\mathrm{c}(\mathrm{p}, \mathrm{z})=\prod_{j=1}^{k} p_{j}^{\eta_{j}^{\prime} z}$

The uncompensated (Marshallian) price elasticity of commodity $i$ with respect to change in the price of good $j$ is

$$
\begin{aligned}
& \epsilon_{i j}=-\delta_{i j}+\frac{1}{w_{i}}\left(\gamma_{i j}-\left[\beta_{i}+\eta_{i}^{\prime} z+\frac{2 \lambda_{i}}{b(\mathrm{P}) c(\mathrm{P}, z)} \ln \left\{\frac{m}{\overline{m_{0}}(z) a(\mathrm{P})}\right\}\right] \times\left(\alpha_{j}+\sum_{l} \gamma_{j l} \ln p_{l}\right)-\right. \\
& \left.\frac{\left(\beta_{j}+\eta_{i}^{\prime} z\right) \lambda_{i}}{b(\mathrm{P}) c(\mathrm{P}, z)}\left[\ln \left\{\frac{m}{\overline{m_{0}}(z) a(\mathrm{P})}\right\}\right]^{2}\right)
\end{aligned}
$$

where $\delta_{i j}=1$ for $i=j$, and 0 otherwise.

The expenditure (income) elasticity for commodity $i$ is

$\mu_{i}=1+\frac{1}{w_{i}}\left[\beta_{i}+\eta_{i}^{\prime} z+\frac{2 \lambda_{i}}{b(\mathrm{P}) c(\mathrm{P}, z)} \ln \left\{\frac{m}{\overline{m_{0}}(z) a(\mathrm{P})}\right\}\right]$

We can also obtain compensated (Hicksian) price elasticity from the Slutsky equation: $\epsilon_{i j}^{C}=\epsilon_{i j}+\mu_{i} w_{j}$. To analyze the expenditure share equations, we assume there is an additive zero-mean error term associated with each of the $k$ expenditure share equations represented (11). The expenditure share equations for the categories in our study are estimated by Iterated Feasible Generalized Nonlinear Least Square (IFGNLS) using QUAIDS command in the STATA 13.1 program.

\section{DATA AND CLASSIFICATION}

\subsection{Data and econometric issues}

We used two data sets to analyze the demands for cultural services in Korea. In order to obtain household spending and socio-demographic information, we employed the quarterly Korean Household Income and Expenditure Survey data over the period 2005 to 2013. The survey interviewed around 28,000 households annually for household spending and income information. Also, it provides a wide range of socio-demographic information on households. This data has been frequently used for studying household demand patterns in Korea (Kim 2006; Lee and Choi 2011; Lee and Lee 2012). The total number of our data used in our analysis is 258,705 households. The other data set used in this study is the quarterly Price Index data provided by the Bank of Korea. After the price index data is recalculated by the weighted average of components for each cultural service item, the data is composed of the corresponding items on the Korean Expenditure and Income Survey. 
Unfortunately, household spending observations on each specific cultural service items do not exist. About $35 \%$ of households inform no outlay for sports and recreation (SR) and about $67 \%$ no outlay for cinema, performing arts, and exhibition (CPE) over three months. According to Ringstad and Løyland (2011), zero observations can incur the censored data problem which affects the distribution of error terms. The Tobit method is a common technique to deal with censored data (McDonald and Moffit, 1980). This is merely a partial method not taking the simultaneous nature of the demand for all goods into consideration. In Ringstad and Løyland studies $(2009,2011)$ using the QUAIDS model, they argued that the impact of the share of zero observations is insignificant, but the inclusion or not of socio-demographic variables matters much more. Thus, instead of the Tobit model, we choose the QUAIDS model to account for the socio-demographic characteristics of Korean households.

\subsection{Classification of expenditure items}

As shown in Table 1, we classify five categories of the expenditure items; Sports and Recreation (SR), Cinema, Exhibition and Performing arts (CEP), Broadcasting and Content (BC), other cultural commodities (OCC), and Non-Cultural Commodities (NCC). Our categories of the expenditure items are partly similar to the categories used by PrietoRodriguez et al. (2005), Ringstad and Løyland (2009, 2011), and Muñiz et al. (2014).

Table 1: Classification of expenditure items and components

\begin{tabular}{|c|c|c|}
\hline Expenditure items & Variable names & Components \\
\hline $\begin{array}{l}\text { Sports and } \\
\text { Recreation }\end{array}$ & $\mathrm{SR}$ & $\begin{array}{l}\text { Sport facilities, Fitness centers, Internet cafés, } \\
\text { Karaoke, Watching sports games, Rental fee for } \\
\text { recreation durable goods }\end{array}$ \\
\hline $\begin{array}{l}\text { Cinema, Exhibition } \\
\text { and Performing arts }\end{array}$ & CEP & $\begin{array}{l}\text { Cinema, Live performing arts, Exhibition, Museum, } \\
\text { Heritage Centre, National Park }\end{array}$ \\
\hline $\begin{array}{l}\text { Broadcasting and } \\
\text { Contents }\end{array}$ & $\mathrm{BC}$ & $\begin{array}{l}\text { Cable TV, Internet Protocol TV, Satellite TV, Online } \\
\text { and mobile content download (e.g. Game, software, } \\
\text { App, etc.) }\end{array}$ \\
\hline $\begin{array}{l}\text { Other Cultural } \\
\text { Commodities }\end{array}$ & $\mathrm{OCC}$ & $\begin{array}{l}\text { Books (excluding text books for public and private } \\
\text { education), Printed matter, Group tours, Culture and } \\
\text { recreation durable goods (i.e. TV, audio, computer, } \\
\text { music- instruments, etc.), Toys, Flowering and } \\
\text { gardening tools, Pet care goods, etc. }\end{array}$ \\
\hline $\begin{array}{l}\text { Non Cultural } \\
\text { Commodities }\end{array}$ & $\mathrm{NCC}$ & $\begin{array}{l}\text { Foods and non-alcoholic beverage, Cigarette and } \\
\text { alcoholic beverage, Furnishing and household } \\
\text { equipment, Clothing and footwear, Healthcare } \\
\text { services, Transportation, Telecommunication, } \\
\text { Education, Eat-out and accommodation, } \\
\text { Miscellaneous goods and services }\end{array}$ \\
\hline
\end{tabular}


Cultural services in the analysis are categorized into three expenditure items, i.e., SR (Sports and Recreation), CEP (Cinema, Exhibition and Performing arts), and BC (Broadcasting and Contents). With the rapid growth of new media in Korea, the proportion of broadcasting and online/mobile content has increased the most out of all cultural service items We expect that the recent increase in the BC item has a significant effect on the expenditure patterns of other cultural services (SR, CEP) and non-cultural commodities. Unlike Montgomery and Robinson (2006) and Ringstad and Løyland (2011), we use the combined performing arts, cinema, and exhibition items, because the Statistics Korea cannot provide separate data for performing arts and cinema and household expenditures in exhibition have very low frequency. According to AtecaAmestoy (2008), Gray (2003), and Seaman (2006), cultural-related activities are mostly influenced by the accumulation of cultural capital and when the separation between sports activities and arts-related activities is clear.

\subsection{Descriptive statistics}

Table 2 provides the descriptive statistics of variables used in the demand system. Notice that the expenditure items for cultural services have a small share of the total household budget, the budget share of SR is $0.06 \%, \mathrm{CEP}$ is $0.02 \%$, and $\mathrm{BC}$ is $0.07 \%$. The price index of SR varies from 91 to 108.2 , CEP from 83.5 to 102.2, and $\mathrm{BC}$ from 97.3 to 102.2 , and OCC from 96.0 to 110.9 . The quarterly average household expenditure is $1,879,000$ won for the period for the period 2005 to 2013.

We excluded Korean household heads aged less than 20 years old, since they cannot independently fulfill most economic activities by themselves. The mean age of household heads is 48 years old. Generally, age plays an important role in deciding arts and culture activities. According to previous studies, a higher age of household head has a negative impact on cultural service expenditure (Ateca-Amestoy 2008; Borgonovi 2004; Gray 2003; Muñiz et al. 2014). Female headed households have positive impacts on the demand of cultural events activities (e.g. performing arts, cinema, exhibition etc.), whereas male headed households have positive impacts on the demand of sports activities (e.g. watching sports games, using sports facility and fitness center, etc.) (Ateca-Amestoy 2008; Borgonovi 2004; Muñiz et al. 2014; Ringstad and Løyland 2006, 2009, 2011). We included the education level of household heads, which can affect the expenditure patterns of cultural services (Ateca-Amestoy 2008; Borgonovi 2004; Palma et al. 2013; Ringstad and Løyland 2006, 2009, 2011). Our data shows that household heads with less than a high school education, a high school education, and more than a college education spend about $25 \%, 39 \%$, and $36 \%$ respectively. In addition to primary socio-demographic characteristics, we control other variables which can affect household expenditure patterns; e.g. household head's labor status, household composition, family size, forms of housing ownership, location, etc.

\section{EMPIRICAL RESULTS}

In order to explain the results of overall demand patterns among items of cultural services in Korea, we check out expenditure and own-price elasticity to investigate Korean households' responsiveness to price and income changes and, then we searched cross-price 


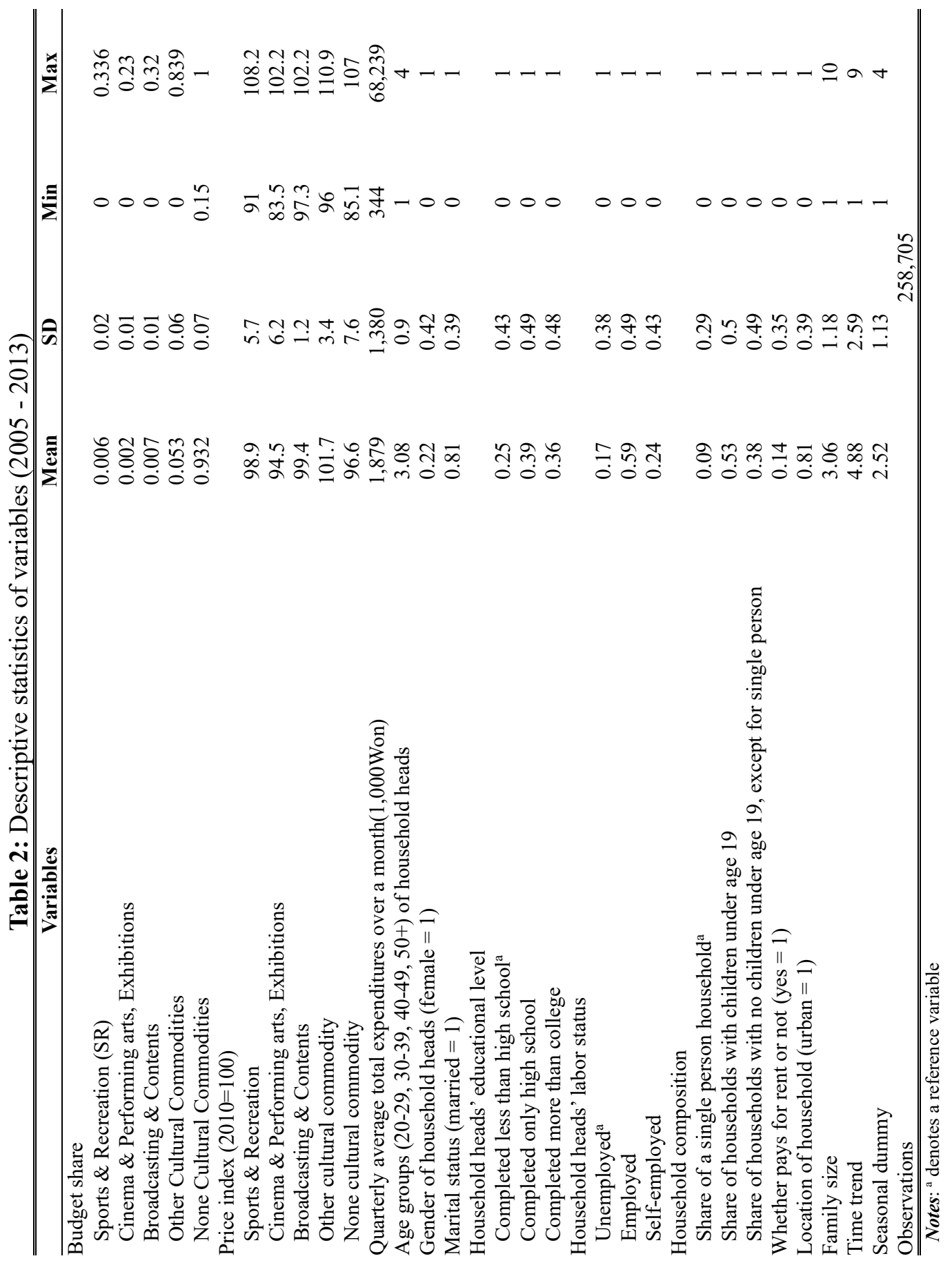


elasticity to examine whether the cultural service items are complements or substitutes. More specifically, this analysis is extended to examine the demand for cultural services by households' characteristics; gender, age, and education level.

\subsection{Tests for model specification and socio-demographic variables}

First of all, let us test the significance of the parameter estimates $\lambda_{i}$ in equation (6) (see all estimated parameters in the appendix). According to Poi (2012), the choice between the original AIDS and the QUAIDS models depends on statistical significance testing $\lambda_{\mathrm{i}}=0$ for $i=1, \ldots, k$. When hypothesis $\lambda_{\mathrm{i}}=0$ is accepted, the quadratic term in a demand model

drops out and we employ the original AIDS model. In table 3, the null hypothesis of model specification is rejected. The estimated parameter $\lambda_{\mathrm{i}}$ is statistically significant for all equations of expenditure items at the $1 \%$ level. It means that nonlinear Engel curves are needed to analyze the cultural service demand. Also, various socio-demographic factors are statistically significant in the QUAIDS model. For example, the null hypothesis that household head characteristics has impacted household expenditure generated a $\chi^{2}$ statistic value of 3100.27, indicating a strong rejection of the null hypothesis. The result means that the characteristics of household head like age, gender, education level should be included in the demand model for cultural services. Therefore, our specified model is suitable for analyzing the cultural service demand in Korea.

Table 3: Result of hypothesis tests

\begin{tabular}{lccc}
\hline \hline \multicolumn{1}{c}{ Null hypothesis } & $\chi 2$ value & DF & p-value \\
\hline $\begin{array}{l}\text { Engel curves are linear in the logarithm of total expenditure } \\
\text { (AIDS VS QUAIDS specification) }\end{array}$ & 4700.57 & 4 & 0.000 \\
$\begin{array}{l}\text { Household head characteristics have not impacted household } \\
\text { expenditure }\end{array}$ & 3100.27 & 39 & 0.000 \\
$\begin{array}{l}\text { Family size has not impacted household expenditure } \\
\text { Household composition has not impacted household expenditure }\end{array}$ & 1460.27 & 4 & 0.000 \\
$\begin{array}{l}\text { Whether or not household pay for rent has not impacted household } \\
\text { expenditure }\end{array}$ & 100.04 & 5 & 0.000 \\
No regional differences in household expenditure & & & 0.000 \\
\hline \hline
\end{tabular}

Notes: This result is calculated by the test command in Stata 13.1 program.

\subsection{Overall demand patterns for cultural service items}

In Table 4, the expenditure (income) elasticity for all cultural service items are positive, which means that the consumption of cultural services increases as income rises. The size of expenditure elasticity for both SR and CEP are greater than 1, implying that these are luxury goods. On the other hand, the expenditure elasticity of BC estimates is close to 0 , implying necessities. In Korea, largest share of cultural expenditure in $\mathrm{BC}$ is broadcasting (CATV, IPTV, or Satellite TV) fees rather than charges for downloading content, and thus the $\mathrm{BC}$ demand seems to have a fixed tendency rather than a sensitive tendency as income 
rises. The expenditure elasticity of CEP (1.37) is similar to that of other countries, while the expenditure elasticity of SR (1.80) is a higher value (Prieto-Rodriguez 2005; Ringstad and Løyland 2009). This result indicates that Korean household's consumption of sports and entertainment (e.g. watching sports games, using sports facility and fitness center, and enjoying recreation, etc.) are more sensitive to income than other countries.

Table 4: Expenditure (income), uncompensated and compensated price elasticity

\begin{tabular}{ccccccc}
\hline \hline & SR & CEP & BC & OCC & NCC & $\begin{array}{c}\text { Expenditure } \\
\text { elasticity }\end{array}$ \\
\hline SR & -3.081 & -0.864 & 0.469 & -0.414 & 2.085 & 1.804 \\
& $(0.511)$ & $(0.145)$ & $(0.113)$ & $(0.156)$ & $(0.422)$ & $(0.021)$ \\
CEP & -2.312 & -2.698 & 0.592 & -0.456 & 3.501 & 1.373 \\
& $(0.389)$ & $(0.213)$ & $(0.111)$ & $(0.128)$ & $(0.368)$ & $(0.016)$ \\
BC & 0.367 & 0.172 & -1.246 & 0.125 & 0.538 & 0.044 \\
& $(0.087)$ & $(0.032)$ & $(0.047)$ & $(0.048)$ & $(0.094)$ & $(0.016)$ \\
OCC & -0.041 & -0.018 & 0.008 & -0.880 & -0.473 & 1.404 \\
& $(0.016)$ & $(0.005)$ & $(0.007)$ & $(0.045)$ & $(0.050)$ & $(0.009)$ \\
NCC & 0.017 & 0.009 & -0.003 & -0.004 & -0.998 & 0.979 \\
& $(0.003)$ & $(0.001)$ & $(0.001)$ & $(0.003)$ & $(0.004)$ & $(0.001)$ \\
\hline \multirow{2}{*}{ SR } & -3.070 & -0.860 & 0.483 & -0.319 & 3.766 & $(0.425)$ \\
& $(0.511)$ & $(0.145)$ & $(0.113)$ & $(0.156)$ & 4.781 & \\
CEP & -2.305 & -2.695 & 0.602 & -0.383 & $(0.369)$ & \\
& $(0.389)$ & $(0.213)$ & $(0.111)$ & $(0.128)$ & 0.579 & \\
BC & 0.368 & 0.172 & -1.246 & 0.127 & $(0.092)$ & \\
& $(0.087)$ & $(0.032)$ & $(0.047)$ & $(0.048)$ & 0.836 & \\
OCC & -0.034 & -0.015 & 0.018 & -0.805 & $(0.050)$ & \\
& $(0.016)$ & $(0.005)$ & $(0.007)$ & $(0.045)$ & -0.085 & \\
NCC & 0.023 & 0.011 & 0.004 & 0.048 & $(0.004)$ & \\
& $(0.003)$ & $(0.001)$ & $(0.001)$ & $(0.003)$ & & \\
\hline \hline
\end{tabular}

Notes: Values in parentheses are standard errors.

Also, Table 4 represents uncompensated and compensated price elasticities estimated at mean values. All of the uncompensated (Marshallian) own price effects are negative as expected. The absolute values for SR, CEP and BC are above unity, implying that Korean households respond sensitively to price changes when purchasing cultural services. In particular, the own price elasticity of both SR and CEP are estimated to be higher than BC. Furthermore, we know that the own price elasticity for all cultural services was higher than the expenditure elasticity, implying that Korean households are more sensitive to price than income.

In order to investigate whether the cultural service items are complements or substitutes, we had to observe the signs of compensated (Hicksian) cross price elasticity among all cultural service items. A positive sign indicates a substitution relationship and a negative sign indicates a complementary relationship. We found that both SR and CEP items are complementary. That is to say, when the price of SR falls, the demand for CEP rises. Conversely, when the price of CEP falls, the demand for SR also rises. In the Ringstad and Løyland (2011) study, they found that t AV media, somewhat similar to BC, is 
complementary with performing arts. However, our results showed that BC is substitute to both SR and CEP. This result may be attributed to the fact that the activities related to SR and CEP have a higher shadow price (e.g. time, monetary and other costs of participation), while those related to the $\mathrm{BC}$ have a lower shadow price. In general, the household who do not want to pay for the shadow price will presumably prefer to BC rather than SR and CEP (Cameron 1995; Getzner 2002; Withers 1980).

\subsection{The distinction of demand elasticities by household characteristics}

As mentioned before, the household demand for cultural services is more influenced by socio-demographic characteristics than other commodity items. Here we examine the demand elasticities of cultural services by primary socio-demographic characteristics of household heads. Table 5 shows the differences of expenditure (income) and price elasticity of cultural services by gender, age, and education level. Note that this section does not consider the compensated (Hicksian) cross price elasticities representing substitution and complementary relationships, because these results are similar to those of the previous section. Thus, we focus on income and price elasticities of three cultural services (SR, CEP, and BC).

Table 5: The Expenditure (Income) and Price Elasticity by socio-demographic factors

\begin{tabular}{lccc}
\hline \hline & SR & CEP & BC \\
\hline Expenditure (income) elasticities & & & \\
Male & $1.700(0.017)$ & $1.357(0.014)$ & $0.067(0.013)$ \\
Female & $2.166(0.036)$ & $1.371(0.019)$ & $0.077(0.017)$ \\
Age group 1 (20-29) & $1.398(0.020)$ & $1.001(0.012)$ & $0.023(0.020)$ \\
Age group 2 (30-39) & $1.643(0.019)$ & $1.186(0.013)$ & $-0.007(0.020)$ \\
Age group 3 (40-49) & $1.742(0.019)$ & $1.344(0.014)$ & $-0.003(0.020)$ \\
Age group 4 (50+) & $1.991(0.027)$ & $1.643(0.023)$ & $0.166(0.012)$ \\
Completed less than high school & $2.423(0.041)$ & $1.886(0.032)$ & $0.180(0.012)$ \\
Completed only high school & $1.858(0.021)$ & $1.410(0.016)$ & $0.053(0.015)$ \\
Completed more than college & $1.532(0.016)$ & $1.169(0.012)$ & $-0.076(0.022)$ \\
\hline Uncompensated price elasticities & & & \\
Male & $-2.973(0.485)$ & $-2.767(0.221)$ & $-1.264(0.051)$ \\
Female & $-3.563(0.629)$ & $-2.496(0.187)$ & $-1.200(0.038)$ \\
Age group 1 (20-29) & $-2.274(0.313)$ & $-1.721(0.090)$ & $-1.225(0.042)$ \\
Age group 2 (30-39) & $-2.825(0.449)$ & $-2.387(0.174)$ & $-1.278(0.053)$ \\
Age group 3 (40-49) & $-3.007(0.493)$ & $-2.708(0.214)$ & $-1.300(0.058)$ \\
Age group 4 (50+) & $-3.514(0.617)$ & $-3.303(0.288)$ & $-1.208(0.039)$ \\
Completed less than high school & $-4.258(0.799)$ & $-3.800(0.351)$ & $-1.186(0.035)$ \\
Completed only high school & $-3.211(0.543)$ & $-2.796(0.225)$ & $-1.251(0.048)$ \\
Completed more than college & $-2.586(0.390)$ & $-2.278(0.160)$ & $-1.312(0.060)$ \\
\hline \hline
\end{tabular}

Notes: Values in parentheses are standard errors.

First, we examined the difference of demand elasticities by gender of the head of the households. Male headed households have lower expenditure and price elasticities than female headed households in the SR category. Female headed households have lower price elasticity than male headed households in the CEP item, even though the expenditure 
elasticity is similar between male and female headed households. Considering female headed households with lower incomes, these results suggest that main customers in sports related activities are male, but those in arts related activities are female. Our results are consistent with other previous researches like Ateca-Amestoy (2008), Castiglione (2011), Gray (2003), and Muñize (2014). Second, examining the demand elasticities by age groups of the head of the households, we found that the expenditure (income) elasticity of SR and CEP goes up as age increases. Households over the age of 50 are particularly sensitive to income and price. This may be due to the fact that in Korea, households over the age of 50 are faced with budget constraints due to rising family responsibilities, for example; a child's marriage, caring for aging parents, preparing for a retirement, etc. Peculiarly, the $\mathrm{BC}$ demand has higher income elasticities in households over the age of 50 than other age groups. This result seems to indicate that SR and CEP activities in this age group have a higher shadow price and BC is substitute for both SR and CEP. Lastly, in regards to the education levels, the expenditure (income) and price elasticity for more educated groups is lower in both SR and CEP. In particular, CEP has the lowest value between SR and CEP. It may be that people with higher education levels prefer to enjoy arts related activities, since they have accumulated cultural capital through formal education or specified arts-related education. (Borgonovi 2004; Seaman 2006; AtecaAmestoy 2008; Wen and Cheng 2013).

\section{CONCLUDING REMARKS}

Through the QUAIDS model including socio-demographic characteristics of Korean households, we examined the demand patterns for cultural services over the period 2005 to 2013. In particular, we examined expenditure and own-price elasticities to investigate households' responsiveness to income and price changes, and cross-price elasticities to examine whether the cultural service items are complements or substitutes. Our findings are as follows.

First, the demands for cultural services in Korean households did sensitively respond to price and income changes. They were far more sensitive to price than income. Especially, Korean household demands for sports related activities (SR) are very sensitive to income. The price elasticities of both SR and CEP are estimated to be higher than BC. Second, our results showed that both SR and CEP are a mutually complementary, while SR and CEP are mutually substitutes for BC. The latter outcome supports the results that the households who do not want to pay shadow price presumably prefer BC rather than SR and CEP. Lastly, we examined the demand for cultural services by household characteristics; gender, age group, and education level. It was discovered that the main customers in CEP are female, while those in SR are male. We also found that both SR and $\mathrm{CEP}$ have higher income and price elasticities in older households, and $\mathrm{BC}$ has higher income elasticity in households over the age of 50. This result indicates that SR and CEP activities in this age group has a higher shadow price and BC is substitute for both SR and CEP. Regarding to the education levels, the income and price elasticity for less educated groups is higher in both SR and CEP. 
Our findings may provide government organizations with information necessary to effectively promote the arts and culture sector. Since the Korean households are more sensitive to price than income, price compensation will be more effective than income compensation to increase the consumption of cultural services. Also, notice that $\mathrm{BC}$ in Korea is substitute for both SR and CEP. This suggests that an increase in BC may mitigate the households' consumption of other cultural services and this pattern appears in households over the age of 50. Thus, government organizations need customized strategies to meet the expanding demands of elderly people. Furthermore, for the educational alienation groups, the government should endeavor to provide more opportunities to enjoy arts and culture, since the price elasticity for less educated groups is increasing in both SR and CEP. Our findings encourage additional studies on cultural services, if we can obtain rich disaggregated data for various fields of cultural services. Our analysis can be applied to capture the differences between the popular arts and pure arts or within a specified cultural services, for example, various genres within a performing-arts.

\section{REFERENCES}

Ateca-Amestoy, V. (2008). Determining heterogeneous behavior for theater attendance, Journal of Cultural Economics, 32(2), 127-151.

Banks, J., Blundell, R., \& Lewbel, A. (1997). Quadratic Engel curves and consumer demand, The Review of Economics and Statistics, 79(4), 527-539.

Borgonovi, F. (2004). Performing arts attendance: an economic approach. Applied Economics, 36(17), 1871-1885.

Cameron, A. C., \& Trivedi, P. K. (2005). Microeconometrics: methods and applications. New York: Cambridge University Press.

Cameron, S. (1995). On the role of critics in the culture industry. Journal of Cultural Economics, 19(4), 321-331.

Castiglione, C. (2011). The demand for theatre: a microeconomic approach to the Italian case. Trinity Economics Papers No. 0911.

Chang, D., \& Serletis, A. (2014). The Demand for Gasoline: Evidence from Household Survey Data, Journal of Applied Econometrics, 29(2), 291-313. doi:10.1002/jae. 2312

Christensen, L., Jorgenson, D., \& Lau, L. (1975). Transcendental logarithmic utility functions. American Economics Review, 65(3), 367-383.

Deaton, A., \& Muellbauer, J. (1980). An almost ideal demand system. American Economic Review, 70(3), 312-326.

Getzner, M. (2002). Determinants of public cultural expenditures: an exploratory time series analysis for Austria. Journal of Cultural Economics, 26(4), 287-306.

Gray, C. M. (2003). Participation. In R. Towse (Eds.), A Handbook of Cultural Economics (pp. 356-365). Cheltenham: Edward Elgar Publishing.

Kim, D. S. (2006). Impact of socio-demographic change on the composition of consumption expenditure: a long-term forecast. KDI Journal of Economic Policy, 28(2), 1 - 49.

Korea Creative Content Agency. (2014). White paper on Creative Industries. Seoul: Korea Creative Content Agency. 
Lee, D. H., \& Lee, D. H. (2012). Increase in telecommunications expenditure and the migration of consumption online: the case of South Korea. The Information Society, 28(2), 61-82.

Lee, J. M., \& Choi, Y. J. (2011). An analysis on determinants of household demand for cultural services. Journal of Industrial Economics and Business, 24(1), 203-217.

McDonald, J. F., \& Moffit, R. A. (1980). The uses of Tobit analysis, Review of Economics and Statistics, 62(2), 318-321.

Montgomery, S. S., \& Robinson, M. D. (2006). Take me out to the opera: are sports and arts complements?: evidence from the performing arts research coalition data. International Journal of Arts Management, 8(2), 24-79.

Muñiz, C., Rodriguez, P., \& Suarez, M. (2014). Sports and cultural habits by gender: an application using count data models. Economic Modelling, 36, 288-297.

Oliver, A. S. (2014). Information technology and transportation: substitutes or complements? Munich Personal RePEc Archive (MPRA) Paper No. 26548.

Palma, M. L., Palma, L., \& Aguado, L. F. (2013). Determinants of cultural and popular celebration attendance: the case study of Seville Spring Fiestas. Journal of Cultural Economics, 37(1), 87-107.

Pawlowski, T., \& Breuer, C. (2012). Expenditure elasticities of the demand for leisure services. Applied Economics, 44(26), 3461-3477.

Poi, B. P. (2002). From the help desk: demand system estimation. The Stata Journal, 2(4), 403-410.

Poi, B. P. (2012). Easy demand-system estimation with quaids. The Stata Journal, 12(3), 433-446.

Prieto-Rodriguez, J., Romero-Jordan, D., \& Sanz-Sanz, J. F. (2005). Is a tax cut on cultural goods consumption actually desirable?: a microsimulation analysis applied to Spain. Fiscal Studies, 26(4), 549-575.

Ray, R. (1983). Measuring the costs of children: an alternative approach. Journal of Public Economics, 22(1), 89-102.

Ringstad, V., \& L Løyland, K. (2009). On the price and income sensitivity of the demand for sports: has Linder's disease become more serious. Journal of Sports Economics, 10(6), 601-618.

Ringstad, V., \& Løyland, K. (2006). The demand for books estimated by means of consumer survey data. Journal of Cultural Economics, 30(2), 141-155.

Ringstad, V., \& Løyland, K. (2011). Performing arts and cinema demand: some evidence of Linder's disease. Applied Economics Quarterly, 57(4), 255-284.

Seaman, B. A. (2006). Empirical studies of demand for the performing arts. In V. A. Ginsburgh \& D. Throsby (Eds.), Handbook of the Economics of Art and Culture (pp. 415-472). Amsterdam: Elsevier.

Wen, W.-J., \& Cheng, T. -C. (2013). Performing arts attendance in Taiwan: who and how often? Journal of Cultural Economics, 37(2), 309-325.

Werck, K., \& Heyndels. B. (2007). Programmatic choices and the demand for theatre: the case of Flemish theatres. Journal of Cultural Economics, 31(1), 25-41.

Withers, G. A. (1980). Unbalanced growth and the demand for performing arts: an econometric analysis. Southern Economic Journal, 40(6), 735-742.

Zieba, M. (2009). Full-income and price elasticities of demand for German public theatre. Journal of Cultural Economics, 33(2), 85-108. 


\section{APPENDIX}

Appendix 1: Estimated parameters of QUAIDS model $(N=258,705)$

\begin{tabular}{|c|c|c|c|c|c|}
\hline & $\begin{array}{c}\text { SR } \\
\text { Coefficient } \\
\text { (SE) }\end{array}$ & $\begin{array}{c}\text { CPE } \\
\text { Coefficient } \\
\text { (SE) }\end{array}$ & $\begin{array}{c}\text { BC } \\
\text { Coefficient } \\
\text { (SE) }\end{array}$ & $\begin{array}{c}\text { OCC } \\
\text { Coefficient } \\
\text { (SE) }\end{array}$ & $\begin{array}{c}\text { NCC } \\
\text { Coefficient } \\
\text { (SE) }\end{array}$ \\
\hline Constant $(\alpha)$ & $\begin{array}{c}-0.068 \\
(0.012)^{* * *}\end{array}$ & $\begin{array}{c}-0.038 \\
(0.004)^{* * *}\end{array}$ & $\begin{array}{c}0.015 \\
(0.003)^{* * *}\end{array}$ & $\begin{array}{c}0.092 \\
(0.009)^{* * *}\end{array}$ & $\begin{array}{c}1.001 \\
(0.015)^{* * *}\end{array}$ \\
\hline $\begin{array}{l}\text { Prices }(\gamma) \\
\text { SR }\end{array}$ & $\begin{array}{c}-0.012 \\
(0.003)^{* * *}\end{array}$ & & & & \\
\hline $\mathrm{CPE}$ & $\begin{array}{c}-0.005 \\
(0.001)^{* * *}\end{array}$ & $\begin{array}{c}-0.004 \\
(0.0004)^{* * *}\end{array}$ & & & \\
\hline $\mathrm{BC}$ & $\begin{array}{c}0.003 \\
(0.001)^{* * *}\end{array}$ & $\begin{array}{c}0.001 \\
(0.0002)^{* * *}\end{array}$ & $\begin{array}{c}-0.002 \\
(0.0003)^{* * *}\end{array}$ & & \\
\hline $\mathrm{OCC}$ & $\begin{array}{l}-0.002 \\
(0.001)^{* *}\end{array}$ & $\begin{array}{c}-0.001 \\
(0.0003)^{* * *}\end{array}$ & $\begin{array}{c}0.0004 \\
(0.0003)\end{array}$ & $\begin{array}{c}0.008 \\
(0.002)^{* * *}\end{array}$ & \\
\hline $\mathrm{NCC}$ & $\begin{array}{c}0.016 \\
(0.002)^{* * *}\end{array}$ & $\begin{array}{c}0.008 \\
(0.0008)^{* * *}\end{array}$ & $\begin{array}{c}-0.003 \\
(0.001)^{* * *}\end{array}$ & $\begin{array}{c}-0.006 \\
(0.003)^{* *}\end{array}$ & $\begin{array}{c}-0.016 \\
(0.004)^{* *}\end{array}$ \\
\hline Expenditure $(\beta)$ & $\begin{array}{c}-0.003 \\
(0.0002)^{* * *}\end{array}$ & $\begin{array}{c}-0.001 \\
(0.0001)^{* * *}\end{array}$ & $\begin{array}{c}0.003 \\
(0.0001)^{* * *}\end{array}$ & $\begin{array}{c}-0.008 \\
(0.001)^{* * *}\end{array}$ & $\begin{array}{c}0.010 \\
(0.001)^{* * *}\end{array}$ \\
\hline Expenditure square $(\lambda)$ & $\begin{array}{c}-0.001 \\
(0.00004)^{* * *}\end{array}$ & $\begin{array}{c}-0.0002 \\
(0.00001)^{* * *}\end{array}$ & $\begin{array}{c}0.001 \\
(0.00002)^{* * *}\end{array}$ & $\begin{array}{c}-0.003 \\
(0.0002)^{* * *}\end{array}$ & $\begin{array}{c}0.002 \\
(0.0002)^{* * *}\end{array}$ \\
\hline \multicolumn{6}{|c|}{ Head of household characteristics } \\
\hline Age_d2 (30-39) & $\begin{array}{c}0.001 \\
(0.0001)^{* * *}\end{array}$ & $\begin{array}{c}0.001 \\
(0.00003)^{* * *}\end{array}$ & $\begin{array}{c}-0.0001 \\
(0.0001)^{* * *}\end{array}$ & $\begin{array}{c}0.002 \\
(0.0002)^{* * *}\end{array}$ & $\begin{array}{c}-0.003 \\
(0.0003)^{* * *}\end{array}$ \\
\hline Age_d3 (40-49) & $\begin{array}{c}0.001 \\
(0.0001)^{* * *}\end{array}$ & $\begin{array}{c}0.001 \\
(0.00002)^{* * *}\end{array}$ & $\begin{array}{c}0.0001 \\
(0.00003)^{* * *}\end{array}$ & $\begin{array}{c}0.004 \\
(0.0002)^{* * *}\end{array}$ & $\begin{array}{c}-0.006 \\
(0.0002)^{* * *}\end{array}$ \\
\hline Age_d4 (50+) & $\begin{array}{c}0.001 \\
(0.0001)^{* * *}\end{array}$ & $\begin{array}{c}0.001 \\
(0.00002)^{* * *}\end{array}$ & $\begin{array}{c}0.0001 \\
(0.00003)^{* * *}\end{array}$ & $\begin{array}{c}0.003 \\
(0.0002)^{* * *}\end{array}$ & $\begin{array}{c}-0.005 \\
(0.0002)^{* * *}\end{array}$ \\
\hline Female_d & $\begin{array}{c}0.001 \\
(0.00003)^{* * *}\end{array}$ & $\begin{array}{c}-0.0002 \\
(0.00001)^{* * *}\end{array}$ & $\begin{array}{c}0.0001 \\
(0.00001)^{* * *}\end{array}$ & $\begin{array}{l}-0.0001 \\
(0.0001)\end{array}$ & $(0.0001)^{* * *}$ \\
\hline Married_d & $\begin{array}{c}0.001 \\
(0.00003)^{* * *}\end{array}$ & $\begin{array}{c}0.0002 \\
(0.00001)^{* * *}\end{array}$ & $\begin{array}{c}0.0001 \\
(0.00002)^{* * *}\end{array}$ & $\begin{array}{c}0.0012 \\
(0.0001)^{* * *}\end{array}$ & $\begin{array}{c}-0.002 \\
(0.0001)^{* * *}\end{array}$ \\
\hline Edu_d2 & $\begin{array}{c}-0.0001 \\
(0.00003)^{* * *}\end{array}$ & $\begin{array}{c}-0.0001 \\
(0.00001)^{* * *}\end{array}$ & $\begin{array}{l}-0.00002 \\
(0.00002)\end{array}$ & $\begin{array}{c}-0.001 \\
(0.0001)^{* * *}\end{array}$ & $\begin{array}{c}0.001 \\
(0.0001)^{* * *}\end{array}$ \\
\hline Edu_d3 & $\begin{array}{c}-0.0003 \\
(0.00003)^{* * * *}\end{array}$ & $\begin{array}{c}-0.0003 \\
(0.00001)^{* * *}\end{array}$ & $\begin{array}{c}0.0001 \\
(0.00002)^{* * *}\end{array}$ & $\begin{array}{c}-0.003 \\
(0.0001)^{* * *}\end{array}$ & $\begin{array}{c}0.0030 \\
(0.0002)^{* * *}\end{array}$ \\
\hline Edu_d4 & $\begin{array}{c}-0.001 \\
(0.0001)^{* * *}\end{array}$ & $\begin{array}{c}-0.0003 \\
0.00002)^{* * *}\end{array}$ & $\begin{array}{c}-0.0002 \\
(0.00004)^{* * *}\end{array}$ & $\begin{array}{c}-0.005 \\
(0.0003)^{* * *}\end{array}$ & $\begin{array}{c}0.007 \\
(0.0003)^{* * *}\end{array}$ \\
\hline Employee & $\begin{array}{c}0.00004 \\
(0.00002)\end{array}$ & $\begin{array}{c}-0.00004 \\
(0.00001)^{* * *}\end{array}$ & $\begin{array}{c}0.0001 \\
(0.00002)^{* * *}\end{array}$ & $\begin{array}{c}0.002 \\
(0.0001)^{* * *}\end{array}$ & $\begin{array}{c}-0.002 \\
(0.0001)^{* * *}\end{array}$ \\
\hline Self-employed & $\begin{array}{c}0.00003 \\
(0.00003)\end{array}$ & $\begin{array}{c}-0.00002 \\
(0.00001)^{* *}\end{array}$ & $\begin{array}{c}0.0001 \\
(0.00002)^{* * *}\end{array}$ & $\begin{array}{c}0.002 \\
(0.0001)^{* * *}\end{array}$ & $\begin{array}{c}-0.002 \\
(0.0001)^{* * *}\end{array}$ \\
\hline Other characteristics & & & & & \\
\hline Family size & $\begin{array}{c}0.0002 \\
(0.00002)^{* * *}\end{array}$ & $\begin{array}{c}-0.0002 \\
(0.00001)^{* * *}\end{array}$ & $\begin{array}{c}0.0001 \\
(0.00001)^{* * *}\end{array}$ & $\begin{array}{c}0.002 \\
(0.0001)^{* * *}\end{array}$ & $\begin{array}{c}-0.002 \\
(0.0001)^{* * *}\end{array}$ \\
\hline Htype_d1 & $\begin{array}{c}-0.002 \\
(0.0001)^{* * *}\end{array}$ & $\begin{array}{c}-0.0004 \\
(0.00002)^{* * *}\end{array}$ & $\begin{array}{c}0.003 \\
(0.0001)^{* * *}\end{array}$ & $\begin{array}{c}-0.07 \\
(0.0003)^{* * *}\end{array}$ & $\begin{array}{c}0.005 \\
(0.0003)^{* * *}\end{array}$ \\
\hline
\end{tabular}


Appendix 1: Estimated parameters of QUAIDS model $(N=258,705)$ (con't)

\begin{tabular}{lccccc}
\hline \hline & SR & CPE & BC & OCC & NCC \\
\cline { 2 - 6 } & $\begin{array}{c}\text { Coefficient } \\
\text { (SE) }\end{array}$ & $\begin{array}{c}\text { Coefficient } \\
\text { (SE) }\end{array}$ & $\begin{array}{c}\text { Coefficient } \\
\text { (SE) }\end{array}$ & $\begin{array}{c}\text { Coefficient } \\
\text { (SE) }\end{array}$ & $\begin{array}{c}\text { Coefficient } \\
\text { (SE) }\end{array}$ \\
\hline Htype_d2 & 0.003 & 0.001 & -0.003 & 0.007 & -0.008 \\
& $(0.0001)^{* * *}$ & $(0.00002)^{* * *}$ & $(0.0001)^{* * *}$ & $(0.0004)^{* * *}$ & $(0.0004)^{* * *}$ \\
Rent_d & 0.0002 & 0.00001 & 0.0001 & -0.0002 & -0.0002 \\
& $(0.00003)^{* * *}$ & $(0.00001)$ & $(0.00002)^{* * *}$ & $(0.0001)$ & $(0.0001)$ \\
Urban_d & -0.0002 & -0.0001 & 0.0001 & 0.001 & -0.0003 \\
& $(0.00002)^{* * *}$ & $(0.00001)^{* * *}$ & $(0.00001)^{* * *}$ & $(0.0001)^{* * *}$ & $(0.0001)^{* *}$ \\
\hline Log-likelihood & & \multicolumn{3}{c}{3030525.1} & \\
\hline \hline
\end{tabular}

Notes: Values in parentheses denote robust standard error, using Stata 13 robust option. We also include seasonal and year dummies in the model. 